
\title{
The Impact of Intravenous Protocols During Labor on Maternal $\backslash$ Newborn Outcomes
}

\author{
Gehan Ebrahim Ghonemy ${ }^{1 *}$, Naglaa Fathy Mahmoud Kotob ${ }^{2}$ \\ ${ }^{1}$ Associate professor of maternal and newborn health Nursing \\ ${ }^{2}$ Lecturer of pediatric nursing
}

Received: March 12, 2017; Accepted: :April 5, 2017; Published:April 14, 2017

*Corresponding author: Dr. Gehan Ebrahim Ghonemy, Associate professor of maternal and newborn health Nursing, Cairo University. E-mail: gghonemy@ hotmail.com

\begin{abstract}
Background: Intravenous therapy instead of oral hydration is common practice in labor. Adequate rehydration has shown a reduction in labor duration. However results of other trials proposed that labor duration could be decreased by administering IV fluids at a rate of $250 \mathrm{ml} / \mathrm{hr}$ which is better than giving such fluids in a rate of $125 \mathrm{ml} / \mathrm{hr}$.
\end{abstract}

Aim: Thus, the aim of the current study was to assess the effect of three protocols of intravenous fluids on the progress of labor and newborn weight loss during the first week post partum.

Design: A descriptive Correlation research design was adopted. In this study in order to investigate the research hypothesis.

Sample: A convenient sample of 150 laboring women (divided to 50 each group) was selected. Partograph, fluid chart and baby weight and diaper sheet was used to collect the data.

Setting: The study was conducted at the labor room in two Egyptian governmental hospitals.

Results: The current research study revealed that the mean time during active phase calculated by hours of the group receiving I.V fluids of $1500 \mathrm{cc}(4.02 \pm 0.99)$ was less than those who received only1000cc and $1250 \mathrm{cc}$ ( $6.82 \pm 1.00$ and $5.34 \pm 0.52$, respectively). There was a statistically significant difference between time during active phase and amount of fluid received through labor ( $p \leq 0.05)$. Also, the newborn weight loss was reported at third and seven day after delivery, and the results revealed a significant difference to their weight loss when the mothers received $1250 \mathrm{ml}$, compared to those who received 1000 or $1500 \mathrm{ml}$.

Conclusion: A significant difference between time during active phase and amount of fluid received through labor, and marked newborn weight loss at 3rd and 7th day after delivery also existed.

Keywords: Intravenous Fluids; Labor Progress; Newborn Weight Loss.

\section{Introduction}

Many women in several countries are not allowed to drink or eat (NPO) during labor. However, NPO practice is not evidence based. "Nothing by mouth" during labor is based on the clinician's fear that a woman will need a general anesthetic and inhale stomach contents during surgery but the odds of this happening are less than being struck by lightning (seven events in 10 million births) as reported by Dekker [9]. Also, reducing hypotension in the mother following epidurals and intrathecal anaesthesia for caesarian sections is one of the major causes for providing intravenous fluids to keep women adequately hydrated during labour [13]. Routine administration of intravenous fluids to keep women adequately hydrated during labour may reduce the period of contraction and relaxation of the uterine muscle, and may ultimately reduce the duration of the labour. It has also been suggested that intravenous fluids may reduce Caesarean Sections (CS) for prolonged labour [8]. Finally, in 2012, Kavitha et al. randomized 293 moms into one of three groups: oral fluids (plain water and coconut water), IV fluids at $125 \mathrm{ml} / \mathrm{hr}$, or IV fluids at $250 \mathrm{ml} / \mathrm{hr}$ [15]. The women in the IV fluid groups were also allowed to have oral fluids. There were no differences between groups regarding length of labor (first stage, second stage, or total length), oxytocin augmentation, or any other complications. There were no differences in complication rates, and no cases of pulmonary edema (However, again, other signs and symptoms of fluid volume overload were not measured).

Intravenous therapy instead of oral hydration is common practice in labor, historically, practitioner administered high dose of glucose solution to combat the development of ketones, more commonly now are isotonic or low dose glucose as high dose and rapid infusion of glucose solution are associated with increased incidence of maternal and fetal hyperglycemia and fetal acidemia. Also, dextrose only solution caused a fall in serum osmolarity and sodium concentration [1]. Regardless of solution type, intravenous therapy predispose women to immobilization, stress, increased risk of fluid overload and does not ensure a nutrient and fluid balance for the demand of labor [24]. A study was conducted by Dawood, Dowswell and Quenby to assess the impact of administering frequent IV fluids to nulliparous women on lowering the labor duration with a random selection of cases [8]. The most important findings of this study revealed a marked reduction in labor duration among women who delivered vaginally and through C.S after administering Ringer's lactate solution. Moreover, this study showed that higher infusion of IV fluids is associated with reduced labor duration. Additionally, women who received dextrose solution showed reduction in labor duration. However results of other trials proposed that 
labor duration could be decreased by administering IV fluids at a rate of $250 \mathrm{ml} / \mathrm{hr}$ which is better than giving such fluids in a rate of $125 \mathrm{ml} / \mathrm{hr}$. Hence, it is clear that administering moderate amounts of IV fluids during the labor process is more beneficial for decreasing the course of labor. As yet, routine administration of intravenous fluids in labor has not been evaluated sufficiently [23].

Fluid overload is one clinical factor that not only affects the mother, but the newborn infant as well. A newborn may appear bloated when the mother receives excess intravenous fluid, the proposed contributor to newborn weight loss [26]. There are also concerns that excessive fluids administered to the mother, may affect the newborn as well. More recent studies found that if mothers received more than $200 \mathrm{ml} /$ hour of fluids, their babies were 3.2 times more likely to experience excess weight loss at three days compared to mothers who had less than $100 \mathrm{ml} /$ hour of fluids [5,19]. Newborn weight loss in the first 2-3 days following birth is a normal, physiologic, and necessary event during the newborn's transition to extrauterine life [25]. Therefore, large weight losses at this time may be a normal physiologic reaction to receiving a large fluid load during labor and may not be associated with hypohydration, inadequate breast milk production, or illness [20].

The normal small volume of breast milk produced in the first 2 days following birth may raise concerns about adequate breast-fed newborns. These concerns are further magnified when breast-fed infants lose $\geq 7 \%$ of their birth weight within 2 day spostnatally. Weight loss following birth is presumably mostly water loss that could result in hypohydration and subsequent hypernatremic dehydration. However, excess fluid loss immediately following birth is a normal and necessary process. Furthermore, newborns exposed to excess fluid intake during labor may need to lose $\geq 7 \%$ of birth weight in the first 2 days following birth in order to achieve euhydration [18]. Therefore, hydration of the mother is recommended as a low-cost method with no complications for the fetus and the mother. NoelWeiss found an evidence related to maternal IV fluids during parturition and related to neonatal output and newborn weight loss; specifically, a correction in fluid balance not requiring intervention [19]. The effect seems time limited, and further weight loss after the first 72 hours is not likely connected to maternal fluids and should not be dismissed as a fluid correction. Therefore observational studies that looking at the relationship between IV fluids during labor and fluid volume overload in babies are needed [9].

Historically, midwifery is one of the oldest professions in the world. It is worth mentioning that deliveries attended by midwives in the United States doubled in the period between 1989 and 2002 from $3.3 \%$ to $7.7 \%$ respectively and then revealed a constant pace of increasing as midwives are the main health care providers . At the same time, the proportion of vaginal deliveries attended by midwives in 2009 was $11.4 \%$ of all births. This increasing rate is similar in other countries to a slight extent. Based on these data, the role of midwives is very crucial. Women seek the care of physicians, midwives and nurses to ensure the safest possible experience for themselves and their babies during labour and birth [12].

Caregivers have a responsibility to provide the highest quality care and efforts should be made continuously towards improvement. One focus for improvement in perinatal care is the lack of attention given to maintaining fluid balance when intravenous therapy (IV) is administered during labour [26]. In spite of evidence-based approach to stop or restrain oral fluid during intrapartum, routine IV fluid management can result in fluid overload, with consequent maternal and newborn outcomes. Therefore, the current study was carried out to help the nurses, midwife and/or physician to assess the effect of use of intrapartum fluid management on maternal outcome. As well, there are no published protocols or guidelines available to address IV fluid management during labor to optimize care for women and their newborn. Research is necessary in healthy newborns to identify relationships among fluids received in utero, newborn weight loss, and hydration, as evaluated with laboratory measures, in the first 2 days following birth. This information will guide clinicians in correctly identifying newborns with inadequate hydration who are in need of supplementary fluids versus newborns with adequate hydration for whom exclusive breast-feeding can be supported and encouraged [18].

Thus the aim of this study was to describe the relationship between the intravenous fluids received during parturition and its impact on labor progress and newborn weight loss after 6 days from delivery.

\section{Methodology}

A descriptive correlation research design was used in order to answer the research questions which are: 1-What is the relationship between intravenous fluid during parturition and labor progress in? 2-What is the relationship between intravenous fluid during parturition and newborn weight loss during the first three days of postpartum?

Sample: One-hundred and fifty full term mothers who had anticipated for normal vaginal delivery were included in this study. Subjects were recruited in this study based on the following inclusion criteria: Nulliparous or multiparous woman, mother age between 20 - 40 years, during active phase of labor (cervix $>3 \mathrm{~cm}$ dilation), low-risk pregnancies, no medical conditions such as diabetes, pre-eclampsia, and did not suffure from any obstetric problems and breast feeding intension. Women, who dehydrated, augmented or induction labors, rapid flow during IV administration were excluded from the study. Also mothers who had high risk babies with Apgar score less than 7 were excluded from the study as well as those with congenital abnormalities.

Setting: Data for this study were collected from two governmental hospitals (Al Mounira hospital, Al Amel hospital). These hospitals provide prenatal, antenatal, labor and delivery and postnatal care.

Tools for Data Collection: A data collection tools were: Maternal assessment tool: to assess the progress of labor include cervical dilatation centimeters measured against duration of labor in hours, descent of presenting part, contractions duration and 
Frequency, alert and action lines [27]. IV fluids chart balance, maternal fluid chart this form is used to calculate the amount of fluid intake and output for mothers recruited in the study, determined the type of fluid, rate per hour and total amount received from admission through labor and delivery. Apgar score tool: is used for rapid evaluation of the infant cardio-respiratory adaptation after birth. Apgar score consists of five objective signs (heart rate, respiratory rate, muscle tone, reflex irritability and color) [4]. These signs are given a score of 0,1 , or 2 evaluated at the first and fifth minutes after delivery and receive a total scores ranging from 0 to 10 . Newborn follows up sheet and baby scales were used to follow the newborn weight changes during the study. Newborn follow up sheet: measure newborn weight starting from delivery until 7 days after. Tool Validity: Tool validity was submitted to five experts in the field of maternal and newborn health nursing and obstetric medicine to confirm its content validity. Modification was carried out according to the panel judgment and pilot study finding on clarity of sentences and the appropriateness of contents. Ethical Consideration: Primary approval was obtained from ethical committee at Faculty of Nursing - Cairo University. After permission was sought from the directors of each selected hospital, and the consultant of each delivery department in the two selected hospitals, explained to the subjects the overall aim of the study before starting. Permission of mothers who will give birth in the selected hospitals was obtained. After the approval being obtained, the investigator approached mothers in the selected hospitals to be invited to take part after explaining the purpose of the study. Written consent was obtained from each laboring women who agree to be participating in this study. Procedures: Before conducting the study, written permission was obtained from each laboring women in each setting after explaining the aim of the study to be agreeing to participate in this study. All laboring women who fit the inclusion criteria and their babies' Apgar scoring not less than 7 were recruited for the study, and interviewed individually since admitted to labor unit to collect the initial required data. After the consent form was signed form with assessment information on admission room. During the course of labor, intravenous fluid information was recorded by the researcher in the form of type of IV fluid (Ringer lactate), rate / hour and the total amount of IV fluid during birth. For assessment of labor progress and outcome, the researcher assessed the uterine contraction, cervical dilatation and effacement, fetal descent every hour regarding the policy of hospital, and duration of each stage of labor by using the partograph. And assess the newborn condition after delivery using Apgar score tool and newborn weight follow up sheet within one week after labor [4]. Regarding newborn weight, a digital electronic scale was used to weigh newborn from birth until the end of first week once daily. The researcher informed the parents to fix every infant scale every time to ensure the internal consistency of the scale, or arrange for scale to be with them throughout that week. The researcher weighted of the newborn at birth without diaper or clothes and recorded this weight. The second day after 24 hours in every morning at exactly ten o'clock the newborn was weighted without clothes or diaper, and the follow-up weight of the newborn up to the seventh day, the same mechanism on the first day. While diaper, the dry diaper was weighed in grams by the researcher first then subtract the total diaper weight after wet, the researcher called the parent daily to record every used diaper which was collected in plastic bag every voiding or defecation and weigh every day, additionally any other output in the form of vomiting was assessed.

Statistical analysis: Statisticalanalysisinterm of means, standard deviation, median, ranges, or frequencies and percentage was used. Comparison of means using t-test for independent samples in comparing two groups when normally distribution occurred. Comparison of numerical variables between more than two groups was done using one way analysis of variance (ANOVA) test with post hoc multiple two group comparisons. For comparing categorical data, Chi-square test was performed.

\section{Results of the study}

Statistical findings of the current study are presented in three main sections each one described the study factors in relation to the amount of IV fluid given $(1000 \mathrm{ml}, 1250 \mathrm{ml}, 1500$ $\mathrm{ml}$ )

\section{I- Distribution of the sample according to their socio- demographical data}

Results indicated that, age of women ranged from 20 40 yrs old; with a mean of (27.29 \pm SD 5.50). Nearly half of them were in the age group $20-25$. Three group of fluid intravenous $(1000 \mathrm{ml}, 1250 \mathrm{ml}, 1500 \mathrm{ml})$ show homogeneity in their data regarding their age as no significant differences were founded (P $<0.05$ ) (Table 1).

\begin{tabular}{|c|c|c|c|c|c|c|c|c|c|}
\hline \multirow{2}{*}{$\begin{array}{l}\text { Age of } \\
\text { mother }\end{array}$} & \multicolumn{2}{|c|}{$1000 \mathrm{cc}$} & \multicolumn{2}{|c|}{$1250 \mathrm{cc}$} & \multicolumn{2}{|c|}{$1500 \mathrm{cc}$} & \multirow{2}{*}{\begin{tabular}{|l} 
Total \\
$\%$
\end{tabular}} & \multirow{2}{*}{$\begin{array}{l}\text { Chi- } \\
\text { square }\end{array}$} & \multirow[t]{2}{*}{$\mathrm{P}$} \\
\hline & $\mathrm{N}=50$ & $\%$ & $\mathrm{~N}=50$ & $\%$ & $\mathrm{~N}=50$ & $\%$ & & & \\
\hline 20-25years & 27 & $54 \%$ & 22 & $44 \%$ & 20 & $40 \%$ & $46.0 \%$ & 8.649 & 0.194 \\
\hline 26-30years & 10 & $20 \%$ & 8 & $16 \%$ & 9 & $18 \%$ & $19.0 \%$ & (a) & \\
\hline 31-35years & 10 & $20 \%$ & 11 & $22 \%$ & 15 & $\begin{array}{l}30 \\
\%\end{array}$ & $23.7 \%$ & & \\
\hline 36-40years & 3 & $6 \%$ & 9 & $18 \%$ & 6 & $12 \%$ & $11.3 \%$ & & \\
\hline
\end{tabular}

Regarding the sample obstetrical profile, results indicated that, three quarter of women $(75.3 \%)$ were multi Para, compared by $(18.3 \%)$ of them were Primi para and only $6.6 \%$ was grand multi Para. Also regarding to the gravid, (66\%) were multi gravida, while (16.7 \%) were Primi gravid (Table 2).

According to the admission examination for women recruited in the study the result found the highest percentage $(51.7 \%)$ has an intact membrane, while (48.3\%) were in spontaneous membrane. Regarding uterine contraction the highest percentage $(91.7 \%)$ had a severe contraction, while $(8.3 \%)$ had a moderate one. Concerning to cervix dilation which ranged from $3-6 \mathrm{~cm}$. The highest percentage $(48.3 \%)$ was $4 \mathrm{~cm}$, 
while $(8.7 \%)$ was $6 \mathrm{~cm}$. Furthermore the effacement was 60 $90 \%$. The highest percentage $(56.4 \%)$ was in $70-80 \%$ while the lowest percentage (8.3\%) in $81-90 \%$. As well as the head station of fetus ranged from $0-3$. The highest percentage $(67 \%)$ was in station zero, while lowest percentage (3.0\%) was 2 stations.
Regarding the effect of the amount of IV fluid on the progress of labour, a Multiple Comparisons test at 95\% Confidence Interval was used and the result in this study did not report any significant difference between cervical dilatation from admission time till full dilatation of the cervix calculated by $\mathrm{cm}$

Table 2 : Distribution of the sample according to their parity and gravity with the amount of fluid received

\begin{tabular}{|c|c|c|c|c|c|c|c|c|}
\hline \multirow{2}{*}{ Number of deliveries } & \multicolumn{2}{|c|}{$1000 \mathrm{cc}$} & \multicolumn{2}{|c|}{$1250 \mathrm{cc}$} & \multicolumn{2}{|c|}{$1500 \mathrm{cc}$} & \multicolumn{2}{|l|}{ Total } \\
\hline & $\mathrm{N}=50$ & $\%$ & $\mathrm{~N}=50$ & $\%$ & $\mathrm{~N}=50$ & $\%$ & $N=150$ & $\%$ \\
\hline Primi Para & 14 & $28 \%$ & 8 & $16 \%$ & 5 & $10 \%$ & 27 & $18.1 \%$ \\
\hline Multi Para & 33 & $66 \%$ & 40 & $80 \%$ & 40 & $80 \%$ & 113 & $75.3 \%$ \\
\hline Grand multi-Para & 3 & $6 \%$ & 2 & $4 \%$ & 5 & $10 \%$ & 10 & $6.6 \%$ \\
\hline \multicolumn{9}{|l|}{ Number of pregnancies } \\
\hline Primi gravid & 12 & $24 \%$ & 8 & $16 \%$ & 6 & $12 \%$ & 26 & $17 \%$ \\
\hline Multi gravid & 30 & $60 \%$ & 34 & $68 \%$ & 34 & $68 \%$ & 98 & $66 \%$ \\
\hline Grand multi gravid & 8 & $16 \%$ & 8 & $16 \%$ & 10 & $20 \%$ & 26 & $17 \%$ \\
\hline
\end{tabular}

Table 3: Distribution of the sample according to the duration of each stage of labor with the amount of fluid received during parturition (number of each group $=50$ )

\begin{tabular}{|c|c|c|c|c|c|c|c|c|c|}
\hline \multirow[t]{2}{*}{ Duration of } & \multicolumn{2}{|c|}{$1000 \mathrm{cc}$} & \multicolumn{2}{|c|}{$1250 \mathrm{cc}$} & \multicolumn{2}{|c|}{$1500 \mathrm{cc}$} & \multirow{2}{*}{$\begin{array}{l}\text { Total } \\
\text { mean }\end{array}$} & \multirow[t]{2}{*}{ F. } & \multirow[t]{2}{*}{ P. } \\
\hline & Mean & S.D & Mean & S.D & Mean & S.D & & & \\
\hline $\begin{array}{l}\text { active phase(by } \\
\text { hours) }\end{array}$ & 6.82 & 1.00 & 5.34 & 0.52 & 4.02 & 0.99 & 5.39 & 132.63 & 0.00 \\
\hline $\begin{array}{l}\text { second stage } \\
\text { (by min) }\end{array}$ & 11.74 & 2.08 & 11.46 & 1.65 & 11.42 & 1.63 & 11.54 & 0.94 & 0.392 \\
\hline $\begin{array}{l}\text { third stage (by } \\
\text { min) }\end{array}$ & 8.54 & 1.45 & 8.28 & 1.30 & 8.07 & 1.35 & 8.30 & 2.974 & 0.053 \\
\hline
\end{tabular}

Concerning duration of active phase calculated by hour, two tailed ANOVA test was used and the results reported that the mean in group received I.V fluids of $1500 \mathrm{cc}(4.02 \pm 0.99$ less than $1000 \mathrm{cc}$ group and $1250 \mathrm{cc}$ group $(6.82 \pm 1.00$ and $5.34 \pm 0.52$, respectively), there was statistically significant difference between the 3 groups in relation to duration of the active phase and amount of fluid received through labor as the duration become shorter when the IV fluid amount progress from 1000,1250 to 1500 the duration was decreased to 6.82 , 5.34 and4.02 respectively, (Table 3 ) and (Figure 1). The duration of the second and third stage of labor did not show significant differences between the groups. and whatever the amount of fluid received during labor $(\mathrm{P} \geq 0.05)$, as in (Table 4). Also, descent of fetal head calculated by $\mathrm{cm}$ didn't indicate any significant differences between station progress and the amount of fluid received during labor $(p \geq 0.05)$. Whilst there were statistically significant differences between mean time during active phase calculated by hour and the amount of fluid received during labor $(p \leq 0.05)$. Concerning time during second stage calculated by minute there were no significant differences $(p \geq 0.05)$. However there were statistically significant differences between time during third stage calculated by minute and the amount of IV fluid especially on $1000 \mathrm{ml}$ and $1500 \mathrm{ml}$ amount $(\mathrm{p} \leq 0.05)$. 
Table 4 :Correlation between progress of labor and the amount of I.V fluid during parturition

\begin{tabular}{|c|c|c|c|c|c|}
\hline $\begin{array}{l}\text { progress of labor as } \\
\text { monitored by }\end{array}$ & $\begin{array}{l}\text { Amount I.V } \\
\text { fluid } \\
\text { (I) }\end{array}$ & $\begin{array}{l}\text { Amount I.V fluid } \\
\text { (J) }\end{array}$ & $\begin{array}{l}\text { Mean } \\
\text { Difference (I-J) }\end{array}$ & $\begin{array}{l}\text { Stander } \\
\text { Error }\end{array}$ & Sig \\
\hline \multirow{3}{*}{$\begin{array}{l}\text { Mean progress of } \\
\text { cervical dilatation } \\
\text { from admission time } \\
\text { by } \mathrm{cm} \text {. }\end{array}$} & $1000 \mathrm{cc}$ & $\begin{array}{l}1250 \mathrm{cc} \\
1500 \mathrm{cc}\end{array}$ & $\begin{array}{l}0.120 \\
0.030\end{array}$ & $\begin{array}{l}0.117 \\
0.117\end{array}$ & $\begin{array}{l}0.916 \\
1.000\end{array}$ \\
\hline & $1250 \mathrm{cc}$ & $\begin{array}{l}1000 \mathrm{cc} \\
1500 \mathrm{cc}\end{array}$ & $\begin{array}{l}-0.120 \\
-0.090\end{array}$ & $\begin{array}{l}0.117 \\
0.117\end{array}$ & $\begin{array}{l}0.916 \\
1.000\end{array}$ \\
\hline & $1500 \mathrm{cc}$ & $\begin{array}{l}1000 \mathrm{cc} \\
1250 \mathrm{cc}\end{array}$ & $\begin{array}{l}-0.030 \\
0.090\end{array}$ & $\begin{array}{l}0.117 \\
0.117\end{array}$ & $\begin{array}{l}1.000 \\
1.000\end{array}$ \\
\hline \multirow[t]{3}{*}{$\begin{array}{l}\text { Descent of fetal head } \\
\text { by } \mathrm{cm} .\end{array}$} & $1000 \mathrm{cc}$ & $\begin{array}{l}1250 \mathrm{cc} \\
1500 \mathrm{cc}\end{array}$ & $\begin{array}{l}0.010 \\
-0.130\end{array}$ & $\begin{array}{l}0.074 \\
0.074\end{array}$ & $\begin{array}{l}1.000 \\
0.235\end{array}$ \\
\hline & $1250 \mathrm{cc}$ & $\begin{array}{l}1000 \mathrm{cc} \\
1500 \mathrm{cc}\end{array}$ & $\begin{array}{l}-0.010 \\
-0.140\end{array}$ & 0.074 & $\begin{array}{l}1.000 \\
0.175\end{array}$ \\
\hline & $1500 \mathrm{cc}$ & $\begin{array}{l}1000 \mathrm{cc} \\
1250 \mathrm{cc}\end{array}$ & $\begin{array}{l}0.130 \\
0.140\end{array}$ & 0.074 & $\begin{array}{l}0.235 \\
0.175\end{array}$ \\
\hline \multirow[t]{3}{*}{$\begin{array}{l}\text { Mean time during on } \\
\text { active phase by hour }\end{array}$} & $1000 \mathrm{cc}$ & $\begin{array}{l}1250 \mathrm{cc} \\
1500 \mathrm{cc}\end{array}$ & $\begin{array}{l}1.485\left(^{*}\right) \\
2.804\left(^{*}\right)\end{array}$ & $\begin{array}{l}0.122 \\
0.122\end{array}$ & $\begin{array}{l}0.000 \\
0.000\end{array}$ \\
\hline & $1250 \mathrm{cc}$ & $\begin{array}{l}1000 \mathrm{cc} \\
1500 \mathrm{cc}\end{array}$ & $\begin{array}{l}-1.485\left(^{*}\right) \\
1.319\left(^{*}\right)\end{array}$ & $\begin{array}{l}0.122 \\
0.122\end{array}$ & $\begin{array}{l}0.000 \\
0.000\end{array}$ \\
\hline & $1500 \mathrm{cc}$ & $\begin{array}{l}1000 \mathrm{cc} \\
1250 \mathrm{cc}\end{array}$ & $\begin{array}{l}-2.804\left(^{*}\right) \\
-1.319\left(^{*}\right)\end{array}$ & $\begin{array}{l}0.122 \\
0.122\end{array}$ & $\begin{array}{l}0.000 \\
0.000\end{array}$ \\
\hline \multirow{3}{*}{$\begin{array}{l}\text { Mean time during } \\
\text { second stage by } \\
\text { minute }\end{array}$} & $1000 \mathrm{cc}$ & $\begin{array}{l}1250 \mathrm{cc} \\
1500 \mathrm{cc}\end{array}$ & $\begin{array}{l}0.280 \\
0.320\end{array}$ & $\begin{array}{l}0.254 \\
0.254\end{array}$ & $\begin{array}{l}0.815 \\
0.628\end{array}$ \\
\hline & $1250 \mathrm{cc}$ & $\begin{array}{l}1000 \mathrm{cc} \\
1500 \mathrm{cc}\end{array}$ & $\begin{array}{l}-0.280 \\
0.040\end{array}$ & $\begin{array}{l}0.254 \\
0.254\end{array}$ & $\begin{array}{l}0.815 \\
1.000\end{array}$ \\
\hline & $1500 \mathrm{cc}$ & $\begin{array}{l}1000 \mathrm{cc} \\
1250 \mathrm{cc}\end{array}$ & $\begin{array}{l}-0.320 \\
-0.040\end{array}$ & $\begin{array}{l}0.254 \\
0.254\end{array}$ & $\begin{array}{l}0.628 \\
1.000\end{array}$ \\
\hline \multirow[t]{3}{*}{$\begin{array}{l}\text { Time during third } \\
\text { stage by minute }\end{array}$} & $1000 \mathrm{cc}$ & $\begin{array}{l}1250 \mathrm{cc} \\
1500 \mathrm{cc}\end{array}$ & $\begin{array}{l}0.260 \\
470\left(^{*}\right)\end{array}$ & $\begin{array}{l}0.193 \\
0.193\end{array}$ & $\begin{array}{l}0.537 \\
0.047\end{array}$ \\
\hline & $1250 \mathrm{cc}$ & $\begin{array}{l}1000 \mathrm{cc} \\
1500 \mathrm{cc}\end{array}$ & $\begin{array}{l}-0.260 \\
0.210\end{array}$ & $\begin{array}{l}0.193 \\
0.193\end{array}$ & $\begin{array}{l}0.537 \\
0.833\end{array}$ \\
\hline & $1500 \mathrm{cc}$ & $\begin{array}{l}1000 \mathrm{cc} \\
1250 \mathrm{cc}\end{array}$ & $\begin{array}{l}-.470\left(^{*}\right) \\
-0.210\end{array}$ & $\begin{array}{l}0.193 \\
0.193\end{array}$ & $\begin{array}{l}0.047 \\
0.833\end{array}$ \\
\hline
\end{tabular}

Level of significance at (P. $\leq 0.05)$

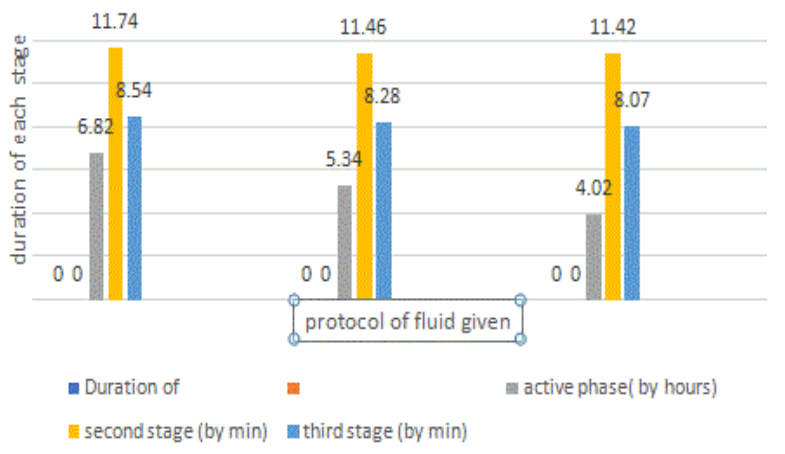

Figure.1: Effect of three protocols of fluid on duration of labour .
In relation to newborn outcomes, the results of the study represents $53.7 \%$ of the newborns were females while $46.3 \%$ were males. Relationship was carried out between the newborn sex and amount of IV fluid given and it reported no significant differences between them; P. value was 0.06 (chi-square $=9.025$ ) as in (Table 5).

The results confirmed that, $95.0 \%$ of the newborns started feeding in 1.00 hour after delivery, while the lowest percentage $1.3 \%$ were newborns who started feeding after 2.00 hours, as in (Table 6).

There was a significant difference between male and female in relation to their weight at birth time when their mothers received $1250 \mathrm{ml}(\mathrm{P} . \leq 0.05)$. Whilst there was no significant difference at birth time between male and female group whom 
Concerning the newborn weight loss in the first day of delivery, the results revealed a significant difference between

Table 5: Distribution of the newborn sex with the amount of fluid received during parturition.

\begin{tabular}{|c|c|c|c|c|c|c|c|c|c|c|}
\hline \multirow{2}{*}{ Sex of newborn } & \multicolumn{2}{|c|}{$1000 \mathrm{ml}$} & \multicolumn{2}{|c|}{$1250 \mathrm{ml}$} & \multicolumn{2}{|c|}{$1500 \mathrm{ml}$} & \multirow{2}{*}{$\begin{array}{c}\text { Total } \\
\text { No. }\end{array}$} & \multirow{2}{*}{$\%$} & Chi- & \\
\hline & $\mathrm{N}=50$ & $\%$ & $\mathrm{~N}=50$ & $\%$ & $\mathrm{~N}=50$ & $\%$ & & & \multirow{3}{*}{9.025} & \multirow{3}{*}{0.06} \\
\hline Female & 22 & $14.70 \%$ & 28 & $18.7 \%$ & 31 & $20.6 \%$ & 81 & $53.7 \%$ & & \\
\hline Male & 28 & $18.7 \%$ & 22 & $14.70 \%$ & 19 & $12.7 \%$ & 69 & $46.3 \%$ & & \\
\hline
\end{tabular}

Table 6: Distribution of the sample according to their time of start of feeding

Time of start of feeding

\begin{tabular}{|l|l|l}
\hline 1.00 hour & Frequency & $\%$ \\
\hline 1.30 hours & 143 & $95.0 \%$ \\
\hline 2.00 hours & 5 & $3.7 \%$ \\
\hline
\end{tabular}

Table 7: Distribution of the newborn weight loss , according to their sex with amount fluid for mothers duringparturition

\begin{tabular}{|c|c|c|c|c|c|c|c|c|c|c|c|c|c|c|c|}
\hline \multirow{3}{*}{$\begin{array}{l}\text { Newborn } \\
\text { birth } \\
\text { weight } \\
\text { By KG. }\end{array}$} & \multicolumn{5}{|c|}{$\begin{array}{l}1000 \mathrm{ml} \\
(\mathrm{N}=50)\end{array}$} & \multicolumn{5}{|c|}{$\begin{array}{l}1250 \mathrm{ml} \\
(\mathrm{N}=50)\end{array}$} & \multicolumn{4}{|c|}{$\begin{array}{l}1500 \mathrm{ml} \\
(\mathrm{N}=50)\end{array}$} & \multirow[t]{3}{*}{ Sig. } \\
\hline & \multicolumn{2}{|c|}{ Male } & \multicolumn{2}{|c|}{ Female } & \multirow{2}{*}{ Sig } & \multicolumn{2}{|c|}{ Male } & \multicolumn{2}{|c|}{ Female } & \multirow{2}{*}{ Sig } & \multicolumn{2}{|c|}{ Male } & \multicolumn{2}{|c|}{ Female } & \\
\hline & $\chi$ & S.D & $\chi$ & S.D & & $\chi$ & S.D & $\chi$ & S.D & & $\chi$ & S.D & $\chi$ & S.D & \\
\hline at birth & 3,308 & 510 & 3,162 & 412 & 0.667 & 3,265 & 406.5 & 3.147 & 388 & 0.002 & 3,181 & 359 & 3,227 & 348 & 0.624 \\
\hline $\begin{array}{l}\text { after } 1 \\
\text { day }\end{array}$ & 3,221 & 509 & 3,060 & 406 & 0.356 & 3,190 & 403.5 & 3.076 & 382 & 0.003 & 3,114 & 371 & 3,108 & 348 & 0.571 \\
\hline $\begin{array}{l}\text { After } 2 \\
\text { day }\end{array}$ & 3,656 & 4.080 & 2,995 & 402 & 0.690 & 3,119 & 402.5 & 2.996 & 399 & 0.007 & 3,031 & 365 & 2,994 & 487 & 0.571 \\
\hline $\begin{array}{l}\text { after } \\
\text { days }\end{array}$ & 3,101 & 507 & 2,939 & 399 & 0.497 & 3,087 & 415.2 & 2.959 & 376 & 0.040 & 2,975 & 361 & 2.969 & 352 & 0.602 \\
\hline $\begin{array}{l}\text { after } \\
\text { days }\end{array}$ & 3,079 & 681 & 3,671 & 4,657 & 0.720 & 3,119 & 417.2 & 3.000 & 365 & 0.064 & 3,020 & 365 & 3.001 & 367 & 0.600 \\
\hline $\begin{array}{l}\text { After } \\
\text { days }\end{array}$ & 3,186 & 502 & 3,026 & 401 & 0.466 & 3,159 & 409.1 & 3,049 & 365 & 0.056 & 3,893 & 4.99 & 3,076 & 348 & 0.856 \\
\hline $\begin{array}{l}\text { After } \\
\text { dayss }\end{array}$ & 3,238 & 500 & 3,080 & 409 & 0.427 & 3,208 & 410,6 & 3.099 & 369 & 0.045 & 3,109 & 407 & 3,138 & 347 & 0.550 \\
\hline $\begin{array}{l}\text { after } \\
\text { day }\end{array}$ & 3,286 & 501 & 3.120 & 410 & 0.367 & 3,259 & 410,3 & 3.676 & 3.957 & 0.556 & 3,172 & 414 & 3.199 & 350 & 0.576 \\
\hline
\end{tabular}


male and female in relation to their weight when their mothers received $1250 \mathrm{ml}$, as the female loss was higher than in male (P. $\leq 0.05)$. Whilst there was no significant difference in the first day between male and female group whom their mothers received $1000 \mathrm{ml}$ or $1500 \mathrm{ml}$ during parturition,(P. > 0.05) (Table, 7).

In regard to the newborn weight loss after second and third, day of delivery, the results reported a significant difference between male and female in relation to their weight when their mothers received $1250 \mathrm{ml},(\mathrm{P} . \leq 0.05)$. Whilst there was no significant difference in the second and third day of delivery between male and female group whom their mothers received $1000 \mathrm{ml}$ or $1500 \mathrm{ml}$ during parturition.

Related to the newborn weight loss after fourth and fifth day of delivery, the results did not report any significant differences between male or female in relation to their weight when mothers received $1000 \mathrm{ml}, 1250 \mathrm{ml}$ or $1500 \mathrm{ml}$.

The newborn weight loss after the sixth day of delivery, revealed a significant difference between male and female when their mothers received $1250 \mathrm{ml}$, (P. $\leq 0.05)$. Whilst there was no significant difference after sixth day of delivery between male and female group whose mothers received $1000 \mathrm{ml}$ or $1500 \mathrm{ml}$ during parturition, (P.> 0.05), as in the (Table 7).

The newborn weight loss after seventh day of delivery indicated no significant differences between male or female in relation to their weight among mothers receiving $1000 \mathrm{ml}, 1250$ $\mathrm{ml}$ or $1500 \mathrm{ml}$, (P.> 0.05), (Table 7).

\section{Discussion}

In relation to the first question regarding the relationship between intravenous fluid during parturition and labor progress, the present study revealed a significant difference between different amount of IV given (1000 cc, 1250 cc, 1500 cc) and the duration of the active phase of the first stage of labor compared to the other phases and stages of labor. The current finding agreed with Dawood, Dowswell and Quenby study who reported that administering frequent IV fluids to nulliparous women lowered the labor duration of 1781 women with a random selection of cases [8]. The most important findings of this study revealed a marked reduction in labor duration among women delivered vaginally and through C.S after administering Ringer's lactate solution. Moreover, this study showed that higher infusion of IV fluids is associated with reduced labor duration $\left(\sum\right.$ mean of duration of active phase, duration of 2nd and 3rd stage were 5.39 hours, 11.54 second and 8.30 second respectively). The results of the current study reported only short duration of the active phase of labour compared to the second and the third one, contributing with increase the amount of IV fluid given. However results of other trials proposed that labor duration could be decreased by administering IV fluids at a rate of $250 \mathrm{ml} / \mathrm{hr}$ which is better than giving such fluids in a rate of $125 \mathrm{ml} / \mathrm{hr}$. Hence, it is clear that administering moderate amounts of IV fluids during the labor process is more beneficial for decreasing the course of labor El Kordy [10]. As of yet, routine administration of intravenous fluids in labor has not been evaluated sufficiently. A Randomized Controlled Trial "RCT" study was conducted by Moghadam, and Rezaeian to compare the impact of oral fluids alone, oral and IV fluids on labor duration and the progression of labor including adverse outcomes among 120 laboring women [17]. The most important findings of this study showed significant difference between groups in labor duration during the first stage while there was no significant difference between groups in the second and no significant difference in the third stage of labor. It is evident that adequate amounts of IV fluids is an essential element in the treatment regimen of laboring woman particularly using the Ringer's lactate solution to decrease labor duration and in particular the prolonged labor. A prospective study was carried out at Shariati Hospital, Tehran by Eslamian, Marsoosi and Pakneeyat among 300 nulliparous women [11]. The sample divided into two groups, group (1) received 125 $\mathrm{ml}$ per hour and group (2) received $250 \mathrm{ml}$ per hour of Ringer solution intravenous. The result revealed that the group that receiving intravenous fluid at a rate of $250 \mathrm{ml}$ per hour the mean \pm S.D. had a duration of labor significantly shorter $(253 \pm 97$ vs. $386 \pm 110 \mathrm{~min} ; \mathrm{P}=0.0001$ ). The duration of labor lasting both more than $10 \mathrm{~h}$ and more than 15 hours was statistically lower ( $4.8 \%$ vs., $\mathrm{P}=0.001$ and vs. $4.5 \% ; \mathrm{P}=0.02$, respectively), and the frequency of oxytocin administration was significantly lower ( $8.1 \%$ vs. $20.4 \%$; $P=0.001$ ) . While another study carried out by Coco, et al. looked to identify the impact of increased IV fluids on labor duration among 80 laboring women using a case control design with random assignment of women on IV fluids group and usual care group [6]. The author used Ringers' lactate on a rate of $250 \mathrm{ml} / \mathrm{hr}$ across women with active labor. The most important findings of this study revealed no difference in labor duration of women in the IV fluids group and with 9.5 hour in the IV fluids group and 9.4 hours in the usual care group. At the same line, there was also no difference in the duration of labor in different labor stages. Hence, this study showed that increased IV fluids does not lower the duration of labor in women with first time pregnancy.

Healthcare providers typically use an infant's weight loss in the first few days of life as a measurement of effective feeding. Supplementation of breastfeeding or increased formula feeding is often recommended when the infant reaches weight loss of seven to ten percent of birth weight $[3,2,18]$

Regarding the second research question addressing the relationship between intravenous fluid during parturition and newborn weight loss during the first 7 days of birth, the results revealed a significant difference between male and female in relation to their weight when their mothers received $1250 \mathrm{ml}$. The female loss was higher than the males' loss at first day and there was a significant difference between male and female in relation to their weight at second and third day after birth. Whilst there was no significant difference between male and female group whose mothers received $1000 \mathrm{ml}$ or $1500 \mathrm{ml}$ during parturition. Related to the newborn weight loss after fourth and fifth day of delivery, the results did not report any significant differences between male or female whose mothers received $1000 \mathrm{ml}, 1250$ 
$\mathrm{ml}$ or $1500 \mathrm{ml}$. While to the newborn weight loss after the sixth day of delivery, revealed a significant difference between male or female in relation to their weight when their mothers received $1250 \mathrm{ml}$. Whilst there was no significant difference after sixth day of delivery between male and female group whom their mothers received $1000 \mathrm{ml}$ or $1500 \mathrm{ml}$ during parturition .In regard to seventh day following delivery, the results did not report any significant differences between newborn male or female in relation to their weight loss either their mothers received 1000 $\mathrm{ml}, 1250 \mathrm{ml}$ or $1500 \mathrm{ml}$. These findings agreed with result of an observational cohort study on 109 participants by Noel-Weiss, et al. who explored the relationship between the intravenous fluids women receive during parturition (the act of giving birth, including time in labour or prior to a caesarean section) and their newborn's weight loss during the first 72 hours postpartum [19]. Specifically, they hypothesized that there would be a positive relationship between maternal intravenous (IV) fluids received during parturition (the act of giving birth) and 1) weight lost by the newborn and 2) neonatal output (i.e., voids and stools) during the first 72 hours post birth. At 60 hours, mean newborn weight loss was $6.57 \%$ (SD 2.51; $\mathrm{n}=96$, range 1.83-13.06\%). When groups, based on maternal fluids, were compared $(\leq 1200 \mathrm{mls}[\mathrm{n}$ $=21]$ versus $>1200[n=53])$, newborns lost $5.51 \%$ versus $6.93 \%$ ( $p=0.03$ ), respectively. For the first 24 hours, bivariate analyses show positive relationships between a) neonatal output and percentage of newborn weight lost $(r(96)=0.493, p<0.001)$; and b) maternal IV fluids (final 2 hours) and neonatal output (r(42) $=0.383, p=0.012$ ). At 72 hours, there was a positive correlation between grams of weight lost and all maternal fluids ( $\mathrm{r}(75)=$ $0.309, p=0.007$ ). They found evidence that maternal IV fluids during parturition are related to neonatal output and newborn weight loss. Therefore, they recommended that a newborn weight measurement at 24 hours replace birth weight as baseline for weight change assessment.

In the same context Chantry, et al. hypothesized that increased newborn weight associated with maternal fluid balance represents loss of excess fluid in the newborn and their findings were significantly related to maternal intrapartum fluid balance, independent of delayed lactogenesis; the adjusted relative risk for excess weight loss more than tripled when positive maternal fluid balance exceeded $200 \mathrm{ml} /$ hour, compared with _100 ml/ hour [5]. This is very similar in magnitude to the relative risk for excess weight loss with delayed lactogenesis. They recommended further research to determine the underlying mechanisms before conclusions can be drawn. Because weight loss may carry a greater risk of subsequent morbidities, increased attention to preventive strategies is indicated. Conversely Lamp and, Macke conducted a study on 200 mother/neonate to examine predictive relationships among intrapartum maternal fluid intake, birth type, neonatal output, and neonatal weight loss during the first 48 hours after birth [16]. They concluded that neonatal weight loss was not significantly related to intrapartum maternal fluid intake. They reported that neonatal weight loss and affected by weight loss within the first 48 hours were type of feeding $(p=.000)$ and average number of wet diapers $(p=.003)$. There are two main differences between their study and the current study: (a) data were collected for 48 hours only versus from first day to seventh day, respectively; with our study, correlations between fluids and weight loss appeared at first day and 72 hours. Fluid amounts and longer data collection period may have accounted for positive findings in this study. Another in agreement study with our results, a retrospective cross-sectional study by Hirth, Weitkamp and Dwivedi examined the relationship of the amount of maternal intravenous fluids (IV) given during labor, and infant maximum weight loss during hospital admission [14]. Through review of medical records for 186 healthy mothers and their infants who delivered at a Baby Friendly certified hospital in southwest Ohio. This Maternal average IV ml per hour positively correlated with infant maximum weight loss. IV fluids per hour were found to be significantly associated with maximum weight loss. For every one percent increase in average ml per hour, the infant maximum weight loss percent will increase by 0.007 . So this study answer the second research question regarding the relationship between intravenous fluid during parturition and newborn weight loss, that increased IV fluids will increase newborn weight loss during the 72 first hours following delivery.

\section{Conclusion and Recommendation}

The results of the study concluded a significant difference between time during active phase and amount of fluid received through labor, this serves the progress the labor, and also relationship between intravenous fluid during parturition and newborn weight loss, that increased IV fluids will increase newborn weight loss and recommended that:

1.Raise awareness of nurses, midwives and physician about the importance of IV fluid during parturition.

2.Carry out other research concerning the effect of intravenous fluid during parturition on labor progress by using a large sample from different regions of the country.

3.Additional research is needed to confirm correlations between maternal IV fluid and infant weight loss.

4.Close monitoring of the number of wet diapers in the first 48 hours and accurate daily weights at birth time can lead to early detection and identification of at-risk neonates to prevent significant weight loss.

\section{References}

1. Allan JF, John FH. Intrapartum maternal glucose infusion increase umbilical cord acidemia. Am J Obstet Gynecol. 2005;177(4):765-796.

2. American Academy of Pediatrics. Policy statement-Breastfeeding and the use of human milk. Pediatrics. 2012;129(3),e827-e841. doi:10.1542/peds.2011-3552

3. Academy of Breastfeeding Medicine. ABM clinical protocol \#3: Hospital guidelines for the use of supplementary feedings in the healthy term breastfed neonate, revised 2009. Breastfeed Med. 2009;4(3):175-182. doi: 10.1089/bfm.2009.9991

4. Apgar V. A proposal for a new method of evaluation of the newborn infant. Curr Res Anesth Analg. 1953;32(4):260-267.

5. Chantry, C., Nommsen-Rivers, L., Peerson, J., Cohen, R., and Dewey, K. Excess weight loss in first-born breastfed newborns relates to maternal intrapartum fluid balance. Pediatrics. 2011;127(1)e171- 


\section{e179. doi:10.1542/peds.2009-2663}

6. Coco A, Derksen-Schrock A, Coco K, Raff T, Horst M, Hussar E. A randomized trial of increased intravenous hydration in labor when oral fluid is unrestricted. Fam Med. 2010;42(1):52-56.

7. Creswell J. Educational research: Planning, conducting, and evaluating Quantitative and qualitative research. New Jersey: Pearson: Merrill Prentice Hall. 2008.

8. Dawood F, Dowswell T, Quenby S. Intravenous fluids for reducing the duration of labour in low risk nulliparous women. Cochrane Database Syst Rev. 2013;(6):CD007715. doi: 10.1002/14651858.CD007715.

9. Dekker R. Copyright Evidence Based Birth 2012. Available at http:// evidencebasedbirth.com/are-iv-fluids-necessary-during-labor /

10.El Kordy, Z. Relationship between intravenous fluid during parturition and labor progress $\backslash$ newborn weight loss in Jordanian governmental hospital, UN publishes Master thesis. 2015.

11.Eslamian L, Marsoosi V, Pakneeyat Y. Increased intravenous fluid intake and the course of labor in nulliparous women. Int J Gynaecol Obstet. 2006;93(2):102-105.

12. Faught BE, Sheehan K, Plyley M, Law M, Montelpare WJ, Wiens L. The Role of Intrapartum Intravenous Therapy and Newborn Weight Loss Challenging the 7\% Rule. Clinics Mother Child Health. 2015;12:181. doi: 10.4172/2090-7214.1000181

13. Hofmeyr GJ, Cyna A, Middleton P. Prophylactic intravenous preloading for regional analgesia in labour. Cochrane Database Syst Rev. 2004;11(4):CD000175. doi: 10.1002/14651858.CD000175

14. Hirth R, Weitkamp T, Dwivedi A. Maternal intravenous fluid and infant weight. Clinical Lactation. 2012; 3(2), 59-63.

15. Kavitha A, Chacko KP, Thomas E, Rathore S, Christoper S, Biswas B, et al. A randomized controlled trial to study the effect of IV hydration on the duration of labor in nulliparous women. Arch Gynecol Obstet. 2012;285(2):343-346. doi: 10.1007/s00404-011-1978-7

16.Lamp JM, Macke JK. Relationships among intrapartum maternal fluid intake, birth type, neonatal output, and neonatal weight loss during the first 48 hours after birth. J Obstet Gynecol Neonatal Nurs. 2010;39(2):169-177. doi: 10.1111/j.1552-6909.2010.01106.x.

17. Direkvand-Moghadam A, Rezaeian M. Increased intravenous Hydration of nulliparous in labor. Int J Gynaecol Obstet. 2012;118(3):213-215 doi: 10.1016/j.ijgo.2012.03.041

18. Mulder PJ, Gardner SE. The Healthy Newborn Hydration Model: A New Model for Understanding Newborn Hydration Immediately After Birth. Biol Res Nurs. 2015;17(1):94-99. doi: 10.1177/1099800414529362

19. Noel-Weiss J, Woodend A, PetersonW, Gibb W, Groll D. An observational study of associations among maternal fluids during parturition, neonatal output, and breastfed newborn weight loss. Int Breastfeed J. 2011;6:9. doi:10.1186/1746-4358-6-9

20.0kumus N, Atalay Y, Onal EE, Turkyilmaz C, Senel S, Gunaydin B. The effects of delivery route and anesthesia type on early postnatal weight loss in newborns: The role of vasoactive hormones. J Pediatr Endocrinol Metab. 2011;24(1-2):45-50.

21.Shaban IA, Hatamleh R, Khresheh R, Homer C. Childbirth practices in Jordanian public hospitals: consistency with evidence-based maternity care? Int J Evid Based Healthc. 2011;9(1):25-31. doi: 10.1111/j.17441609.2010.00197.x

22. Sheehan K. The role of intrapartum intravenous therapy and method of delivery on newborn weight loss: Challenging the $7 \%$ rule. Master thesis. 2009. Retrieved from http://dr.library.brocku.ca/ bitstream/ handle/10464/2925/.
23. Mahnaz Shahnazi , Manizheh Sayyah Meli, Fariba Hamoony, Farnaz Sadrimehr, Fatemeh Ghatre Samani, Hossein Koshavar. The Effects of Intravenous Hydration on Amniotic Fluid Volume and Pregnancy Outcomes in Women with Term Pregnancy and Oligohydramnios: A Randomized Clinical Trial. J Caring Sci. 2012;1(3):123-128. doi: $10.5681 /$ jcs.2012.018

24. Singata M, Tranmer J. Restricting oral fluid and food intake during labor (Review). Cochrane Collaboration and published in the Cochrane library. 2013. doi: 10.1002/14651858.CD003930.

25. Tender JA, Janakiram J, Arce E, Mason R, Jordan T, Marsh J, et al. Reasons for in-hospital formula supplementation of breastfed infants from low-income families. J Hum Lact. 2009;25(1):11-17. doi: $10.1177 / 0890334408325821$

26. Watson J, HodnettE, Armson BA, Davies B, Watt-Watson J. A randomized controlled trial of effect of intrapartum intravenous fluid management on breastfed newborn weight loss. J Obstet Gynecol Neonatal Nurs. 2012;41(1):24-32. doi: 10.1111/j.1552-6909.2011.01321.x.

27.WHO: World Health Organization Partograph in Management of labor. 2000;343:1399-1404. 